\title{
ACRL in Miami-taking the network plunge
}

\section{Highlights of ACRL programs at ALA's Annual Conference}

$\mathbf{A}$ CRL members will remember ALA's 113th Annual Conference, held in Miami Beach, for its hot weather and its sizzling coverage of the Internet. Total conference attendance was 12,627 members, exhibitors, and guests, including 8,025 paid registrations-down about a third from the 1993 Annual Conference in New Orleans. For ACRL members, the conference proved to be an exciting one. Covering the Internet and its resources, leadership issues, communication techniques, network technology, and a variety of other topics, ACRL's programs offered many learning experiences for attendees. Below are highlights of some of the programs. ( $E d$. note: The University Libraries Section's report will appear in the October issue.)

\section{ACRL Leodership Institute}

"The Future Ain't What It Used to Be," the theme of the day-long ACRL Invited Leadership Institute Preconference, set the tone for planning and deliberations at all levels of the division throughout the ALA Conference. Dadie Perlov, president of the Consensus Management Group, who also was a consultant to ALA's Self-Study Committee.

She said, "ACRL is not a business. The goal of business is to make money; the goal of a service organization is to provide service to members." The leaders were reminded that the division has only one employee-the executive director-and the focus of ACRL's mission statement should be on librarians, with division benefits well articulated and at the heart of all programs and activities. The Board should determine outcomes and monitor results and let staff and other units be responsible for the "hows." ACRL should remain at least as financially sound as it is now.

The potential for membership should stem from the proportion of the possible universe of members. The results of the ACRL Membership Survey should be kept in perspective because organizational statistics indicate that members with the highest involvement in an organization (and some dissidents) are the most participatory, which excludes input from potential members and unambitious members. Perlov suggested it might be more effective to survey the 10 newest members, 10 members who most recently quit the division, and 10 potential members to ascertain what members want in ACRL.

Other suggestions included: keeping the structure and governance at a minimum, reviewing old policies to see if they are still necessary, and refraining from micromanaging staff and committees. If something is added, give something up. Be on the cutting edge, which means possibly breaking up the hierarchy. Look for (perhaps unlikely) collaborators outside the organization as well as inside.

Finally, evaluate the planning efforts by asking, "Did the organization grow? Did the organization help the members learn and grow?" Perlov concluded by advocating risk-taking, defining "experience as the name we give to our mistakes."-Barbara Wittkopf, Louisiana State University

\section{How to teach the Internet}

In the belief that the combined strengths of ACRL sections serves to elevate the quality of conference programs, the Bibliographic Instruction Section and the College Libraries Section joined together to offer the program "Beyond the F1 Key: Thinking and Teaching the Internet within the Curriculum." 
Before an audience of more than 500 people, Gerald Nosich, professor of philosophy at the University of New Orleans and noted authority on critical thinking, provided program participants with a working definition of critical thinking, discussed the importance of promoting it within a discipline, and offered numerous examples of the concept. Critical thinking, Nosich said, is not problem-solving, but rather a process of asking the question, trying to answer by reasoning, and acting in accord with the reasoning. He also reviewed the importance of the affective traits of intellectual courage and humility in critical thinking.

As a researcher of the inherent benefits and liabilities within the electronic dissemination of information, Kevin Roddy, University of California-Davis, provided the audience with a nonlibrary faculty perspective on the educational reasons for teaching the Internet. He pointed out that while the Internet has made scholarship more widely available than ever before, it has also "produced chaos that is often at best only a waste of time." Describing student assignments and projects in his own humanities and computing courses, Roddy stressed the importance of enhancing the Internet's advantages through careful course design.

Following the guest presenters, Ilene Rockman of California Polytechnic State University, Mary Jane McDermott Cedar Face of Southern Oregon State College, and John Stachacz of Dickinson College offered specific examples of how they integrated the teaching of Internet resources into the curricula of their home campuses.-Keith Gresham, University of Colorado-Boulder

\section{Gender differences in communication}

In "Making the Net*Work: Is There a Z39.50 for Gender Communication?," cosponsored by the Education and Behavioral Sciences and Women's Studies sections of ACRL, Becky Mulvaney, Florida Atlantic University began her presentation, "Gender Differences in Communication: An 'Inter-Cultural' Experience," by stating that gender is an influence on and a product of com- munication. Mulvaney noted that three primary elements of intercultural communicationworld view, language usage, and nonverbal communication-had particular bearing in terms of communication across gender. Women tend to have a slightly different world view than men; they tend to use language in a different way (women generally see talk as the essence of a relationship, whereas men use language to assert themselves); and women respond to nonverbal communication differently than men. Mulvaney concluded that we should not assume similarity between the sexes, and pointed out the problems caused by our tendency to evaluate other cultures (i.e., other genders) as inferior.

In her talk "Gender Differences in Computer-Mediated Communication: Bringing Familiar Baggage to the New Frontier," Susan Herring, University of Texas at Arlington, made two opening observations based on her research: women and men have recognizably different styles of communication, and women and men have different communication ethics.

Typical of men's style on the net is adversaryism, put-downs, and lengthy postings, and they tend to be authoritative in tone. Women tend to express themselves via supportiveness and attenuation - they do a lot of hedging, apologizing, and appealing to the group. Women also tend to allow for alternative points of view far more than men do. Herring also discussed the practice of flaming (the expression of strong negative emotion, often including personal insult), noting that "virtually only men flame," and therefore "any explanation of

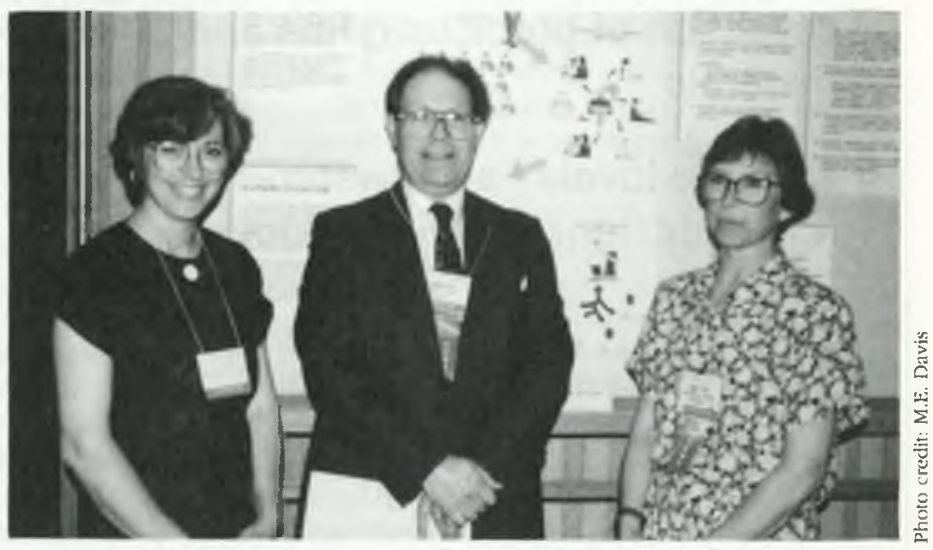

Patricia Kreitz (left) and Janet Fore (right) of STS coordinated that section's very successful all-day Internet training session in support of ACRL President Tom Kirk's (center) theme of networking. 


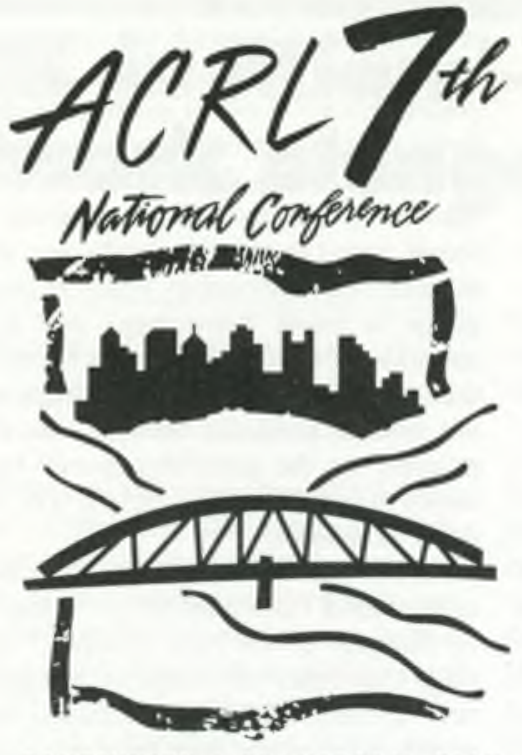

CONTINUITY \& TRANSFORMATION

The Promise of Confluence

March 29 - April 1, 1995, Pittsburgh, Pennsylvania

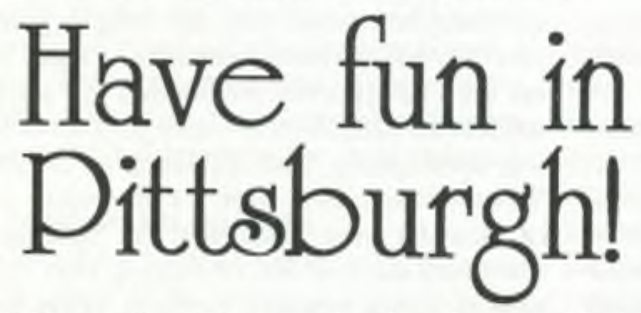

Meander through the beautiful Carnegie Museum and view its collection of precious gems and minerals.

Tour the lovely Fallingwater-a house designed by Frank Lloyd Wright.

\section{- Visit the libraries of Carnegie Mellon University and the University of Pittsburgh.}

\section{March 29-April 1, 1995!}

flaming must take gender into account." Herring mentioned three ways that this situation can be addressed: 1) support women-centered lists, 2) educate online communities about male-dominated behaviors, and 3) participate in any way possible in the formation of netiquette rules.

James V. Carmichael, University of North Carolina, responded with a lively discourse which included anecdotes about some of the more notorious "female pioneers in librarianship." He noted that the discussion of gender parity in librarianship has a long history, citing the "weaker sex debate" in Library Journal in the 1930s. In the present time, Carmichael feels that the discrepancy between salary levels for women and men in librarianship is of particular concern. He noted that the "network presents a situation which is potentially gender-free," a situation in which one is "responding to a voice rather than a gender."

Note: The papers presented at this program will be available on LIBWAT-L (send the command "SUB LIBWAT-L your name" to LISTSERV@UBVM or LISTSERV@ UBVM.CC.BUFFALO.EDU via a mail message (as the first line in the body of the mail, not the Subject: line).Jessica Grim, Oberlin College

\section{Information flows out of the former Soviet Union}

Speakers at the Slavic and East European Section's program, "Finding Out about the Former Soviet Union and Eastern Europe: Improvements in Customer Services," examined changes in the nature and availability of reference, business, and electronic sources of information on Russia and Eastern Europe

Alan Pollard, University of Michigan, noted that the abundance of material that is emerging from Eastern Europe as a result of political changes has been a "windfall for researchers, but a problem for librarians to manage." Russian and East European state subsidies have ended 
and as a result, marketing forces which target Western countries are driving the publishing industry in these countries. While there has been a proliferation of new material, some traditional sources of informationlike scholarly publications and national bibliographies-are declining.

Jeanie M. Welch, University of North Carolina-Charlotte, reported that commercial publishers are scrambling to produce new works on doing business in Russia and Eastern Europe. In addition, many established economic resources have expanded their coverage; for example, European Marketing Data and Statistics now includes data for Eastern Europe. Welch warned librar-

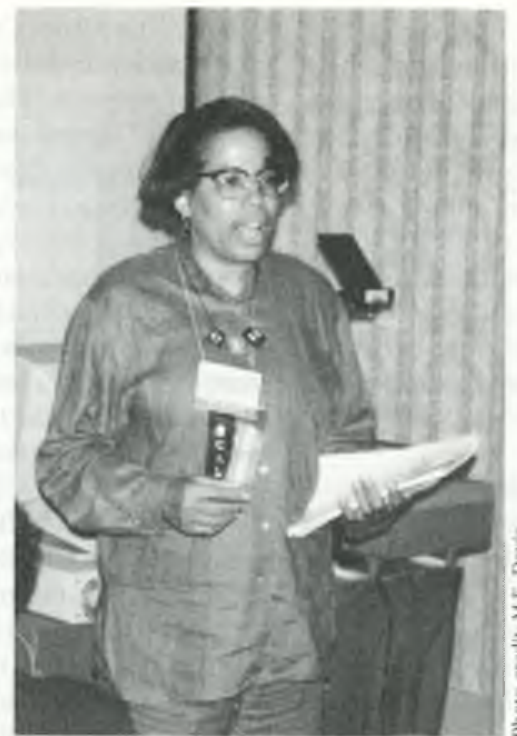

Gladys Smiley Bell, of Kent State University, was one of the many instructors participating in STS' Internet training session. sentations throughout the day.

The program featured workshop-like sessions on such diverse subjects as astronomy, anthropology, biology, business, chemistry, literature, and women's studies. There were also instructional sessions on various Internet tools and on teaching about the Internet, as well as poster sessions.

The standing-room-only sessions attracted participants from all types of libraries. Although there were some technical difficulties with telecommunications for live demonstrations, the presenters were prepared with back-up transparencies and/or presentation software. Handouts and/or presentation ians to be wary of works that are simply an expensive repackaging of data. In response to a question from Molly Molloy, Hoover Institution, Welch recommended several business titles, including Consumer Eastern Europe, published by Euromonitor.

Casey Palowitch, University of Pittsburgh, demonstrated the REES (Russian and East European Studies) Home Pages, a hypertext guide and gateway to Russian and Eastern European Internet resources accessed through the World Wide Web. The REES Home Pages is compiled and maintained by the University of Pittsburgh, and provides access to material that ranges from multimedia exhibits to a text of The Brothers Karamazov. The URL for Pittsburgh's REES Home Pages is: http://www.pitt.edu/ cjp/ rees.html. While noting the tremendous potential of this new project, Molloy raised some of the important issues (such as access, archiving, and regulation) that will need to be addressed in the future.-Julie Swann, University of $\mathrm{Ne}$ braska-Lincoln

\section{Covering the full range of Internet resources}

"Scholarly Resources on the Internet: Beyond the Basics," sponsored by ACRL's Science and Technology Section (STS), successfully offered over 25 different hour-long subject-specific pre- materials are being gathered by the conference planners in an electronic format so the materials can be made available electronically on the ACRL gopher.-Gayle Baker, University of Tennessee

\section{European fiction amidst change}

The 1994 Western European Education Section's annual program, "Emerging European Writing: Visions and Voices of the New Europe," aimed to discuss and debate the impact that some of the recent, momentous sociopolitical changes its culture and writing.

Giuliana Menozzi, University of Florida, speaking on the current publishing scene in population reads one book a year and that this publishing crisis is having a detrimental effect on the publication of serious fiction. Aida Bamia, University of Florida, surveyed French fiction by authors of Arabic descent, the Beur, characterizing this literature as essentially one of generational and cultural tensions. The neglected but imaginatively rich contemporary Portuguese literature was surveyed by Richard Preto-Rodas, University of South Florida. He characterized it as drawing both on European literary traditions and the magic realism of Latin America. Finally, Siegfried Mews, University of North Carolitaking place in Western Europe have had on Italy, emphasized that only 50 percent of the 
na-Chapel Hill, spoke on the German literary and intellectual post-unification debate which has led German writers to assess the sociopolitical ramifications of a united Germany, and to redefine Europe and Germany's role in it.

Each speaker also produced a bibliography which was handed out at the program. (Interested readers can request them from me: Frank Di Trolio, 140 Library West, University of Florida, Gainesville, FL 32611; e-mail: frandit (anervm.nerdc.ufl.edu.)_Frank Di Trolio, University of Florida, Gainesville

\section{Studying Caribbean cultures}

The ACRL Anthropology and Sociology Section program, "Cultures of the Caribbean: Diversity and Transformation, Research and Resources," began with a bibliographical history of the primary ethnic group of the Caribbean: AfricanAmericans. The general traditions of the anthropological study of the region were outlined: 1) the Herskovitsian approach, which emphasizes African cultural survivals; 2) the post-World War II/Columbia University area studies approach; and 3) the structural-functionalist approach of British social anthropology. Within this context, seminal writings and major subsequent works were discussed. The books and journal articles cited ranged in time of publication from 1906 into the 1990s.

Miami's Hispanic population grew from five to 49 percent between 1960 and 1990 and is projected to be an approximate 55 percent in 1994. This Hispanic population is predominantly Cuban, with more than half of the one million Cubans living in the U.S. concentrated in

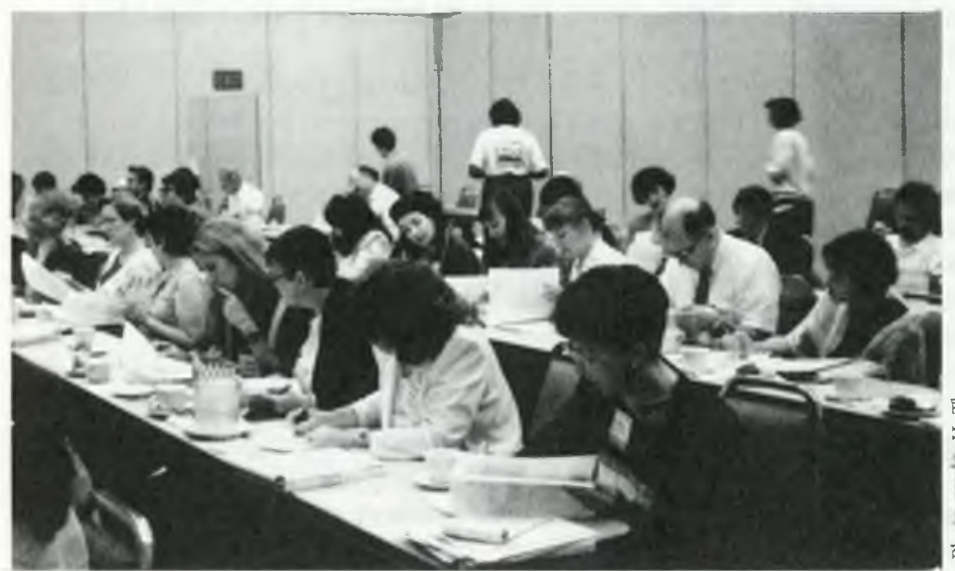

ACRL members worked hard during the leadership session led by consultant Dadie Perlov.
Miami. The Miami Cubans differ from Hispanic populations in other large cities in quite important respects. They are more economically successful (being mostly people from the middle and upper classes who immigrated for political, not economic, reasons), have lower birth rates, are politically conservative, and have politically empowered themselves.

CD-ROM products, online searching services, and Internet resources useful to study and research on the Caribbean and Latin America were described in the session. Some impressive CD-ROM software has begun to be issued in Mexico. CODICE 90, a Mexican product which contains the final results of Mexico's 1990 census of population and housing, was demonstrated. The program concluded with a demonstration on searching for Latin American and Caribbean studies materials in the enhanced computerized catalog of the Florida International University Library.-Jim Williams, University of Illinois at Urbana-Champaign

\section{Binding together a multicultural society}

"Is a shared value system, which binds together members of a society, possible in a multicultural situation?" Three ACRL sections thought this question, posed by David HayesBautista in a recent issue of the Chronicle of Higher Education was significant enough to use as the focus of their jointly sponsored program, "Binding Together a Multicultural Society: Challenge for the Academy." The Afro-American Studies Librarians, Arts, and Law and Political Science sections of ACRL were joined by the ALA Government Documents Round Table in the presentation of Sheldon Hackney, Director of the National Endowment for the Humanities, as the keynote speaker. The thought-provoking program also included a reactor panel consisting of Patrick Coggins, Stetson University, and Olga Garay, MiamiDacte Community College.

Hackney said that the United States must come to grips with its 


\section{A BETTER WAY TO SEARCH DATABASES}

W e started in 1985, database searchers committed to better search software design. We became the premier vendor of Medline, then expanded our catalog to other databases. Last year we won Information World Review's PRODUCT OF THE YEAR for faster, easier search software. But a better way means meeting the evolving needs - individual and campus wide - of today's library users.

$\triangle$ nnouncing OVID: a database interface Aso flexible it molds itself to your search environment.

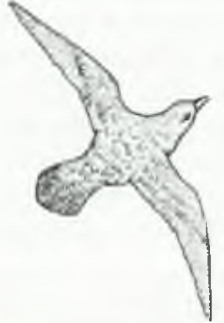

With OVID you're free to move from one operating system to anotber without retraining. OVID's Common User Interface assures identical functionality in DOS, Windows and UNIX.

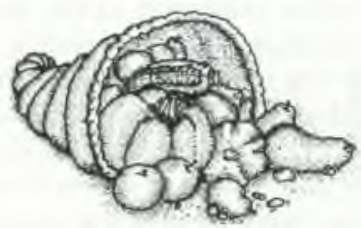

There's an unprecedented array of search tools - indexes, thesauri, limits and fields - many never before available in an interface. They're all standard OVID features.

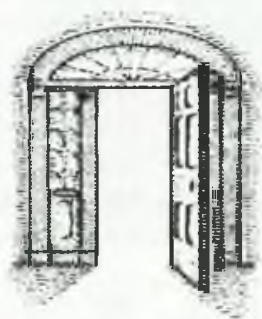

A baven for beginners, OVID's

Easy Mode has on screen prompts. The more experienced can pull-down menus showing an array of search options. Experts will feel at home using online syntax.

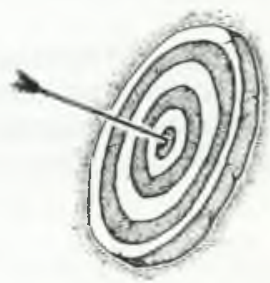

Search with natural language if you like. OVID mapping cuts through the mystery of controlled vocabularies, homing in on precisely matching subject beadings.

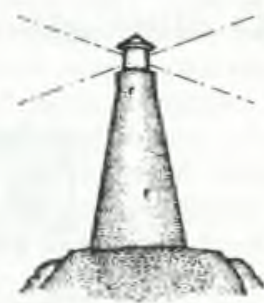

HELP for every search function is context-sensitive and on screen, never more than a keystroke or mouse click away.

\section{OVID. A better way to search ERIC, Current Contents', PsycINFO', Medline, Readers' Guide Abstracts, EMBASE and more.




\section{Order your Annual Conference audiocassettes}

Audiocassettes of selected ACRL programs from the 1994 ALA Annual Conference in Miami Beach are now available. Each program consists of two cassettes and sells for $\$ 24$ unless otherwise noted.

Taking the Network Plunge: Remote Library Users and Electronic Networks. Order no. ALA409

What Me-A Leader? Order no. ALA410

Women and Technology: The Virtual Library and the Disadvantaged Majority. Order no. ALA411

Who's Who: The Changing Roles of Librarians and Support Staff. Order no. ALA426

Educating and Training Special Collections Librarians: The Network of Expectations and Opportunities. $(\$ 36,3$ cassettes). Order no. ALA430

multicultural society. It must find ways to develop collective allegiances and solve common problems, yet recognize distinctive group differences. It must address issues relating to national cohesion, loyalty, and identification with the whole. To reach this goal, he said, "we must begin a national conversation that includes all voices from all groups." There must be "a new birth of freedom" for all Americans.

Reacting to the keynote address, Garay and Coggins agreed that a massive national dialogue open to all would be a noble goal, although difficult to accomplish. Many of the cultural groups do not have democratic orientations nor a culture of free speech because of historical circumstance. The reactors strongly recommended equal opportunity, equal justice, and economic parity as proactive means of binding the cultures together. In any solution, differences must be deemphasized and commonalities celebrated for the common good.-Doris Hargrett Clack, Florida State University

\section{Distance education and electronic networks}

ACRL's Extended Campus Library Services Section hosted 270 participants at its program "Taking the Network Plunge: Remote Library Users and Electronic Networks." Focusing on the rapid advancement of electronic networks, distance
Going Home Again: Return to the Roots. (\$36, 3 cassettes). Order no. ALA445

Making the NET'WORK: Is There a Z39.50 in Gender Communication? Order no. ALA446

Beyond the F1 Key: Thinking and Teaching the Internet within the Curriculum. Order no. ALA451

Geographic Information Systems: A New Service Opportunity for Libraries. Order no. ALA462

Audiocassettes for other programs are also available. Call, write, or fax your order or a request for a complete order form to: Teach 'em, 160 East Illinois St., Chicago, IL 60611; voice: (312) 467-0424 or (800) 225-3775; fax: (312) 467-9271. You may pay by check (payable to Teach 'em) or by credit card (VISA, MC, AMEX).

education, and off-campus library services, the program was cosponsored by LITA's Telecommunications Interest Group.

The first speaker, James Neal, Indiana University, focused on distance education (DE) and the recent shift away from teaching and teachers toward learning and learners. He described the new "majority student," the older, part-time, married, working student as the primary focal point for higher education in the future. He described the many reasons for getting involved in $\mathrm{DE}$, including economic, governmental, and global. He discussed the definitions and goals of DE, reminding us that equity of access and lifelong learning, as well as access to the greater talent-base, were all principal in helping us participate in the global community.

Kate Wakefield of WLN demystified the telecommunications technology. She discussed the many ways of becoming connected to the Internet to provide access to networked information to distance learners, and shared handouts with a cost and services comparison of the dial-access and dedicated Internet connections.

Dan Barron, University of South Carolina, talked about the impact of the rapid changes in DE and networked technologies on the library staff who have to cope with them. He encouraged interaction and participation among 


\section{Local service. Clobal support. With infernational serials service from EBSCO.}

No matter where your organization is located or from which countries your titles originate, with 27 offices worldwide EBSCO can be both your local and your global vendor. With one call to EBSCO you can effectively order your North American serials subscriptions through your EBSCO regional office here in the U.S., your European titles through our appropriate European offices, and even your Asian and Australian titles through the corresponding EBSCO overseas offices. And when you deal with only one serials vendor, your staff benefits through increased efficiency and more valuable serials management reports.

\section{Subscribe globally. Order locally. With EBSCO.}

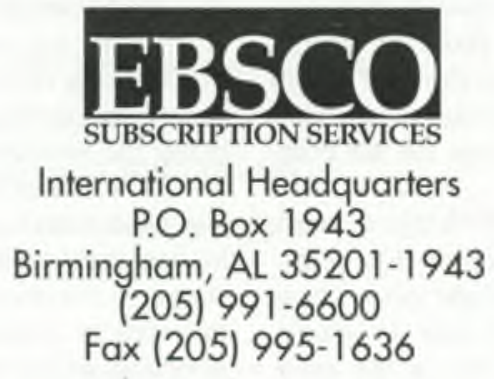

EBSCO operates nine offices in the U.S. and two in Canada. Offices also located in: Australia, Brazil, Czech Republic, France, Germany, Itoly, Korea, The Netherlands, New Zealand, South Africa, Spain, Taiwan, Thailand, Turkey and the United Kingdom. 


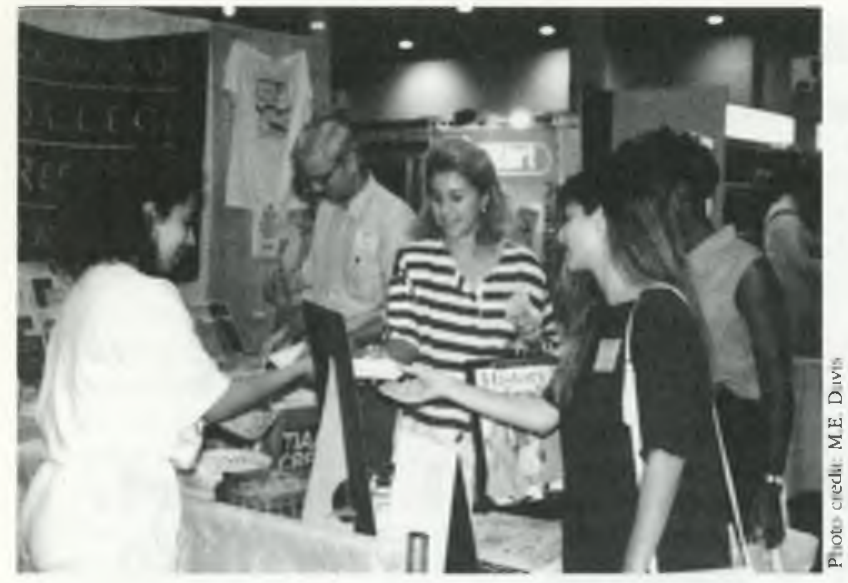

The raffle for Pittsburgh prizes held at ACRL's membership booth in Miami produced 35 winners.

the audience and concluded with the observation that the librarian's role has not really changed over the years; the means by which he or she provides access and instruction have changed. Barron's review of the literature suggests that organizational and individual change and preparation for the future should include the following: a vision, a team approach, consensus-building skills, communication skills, communication, trust and respect, thinking with new perspectives, empowerment and positive self-regard, intrinsic vs. extrinsic rewards, a work ethic, risk-taking, and the time necessary to do the job.-Thomas Abbott, University of Maine at Augusta

\section{Techniques for learning the net}

Anne Lipow opened the Community and Junior College Libraries Section's program, "Bringing Your Staff Up to Speed on the 'Net', "with an original cartoon in which an eager staff member reads the following message on his computer screen:

"Welcome to the Internet. With this network you can find what you need easily. Just punctuate properly and spell perfectly. Also, know UNIX, VMS, CMS, and in 3270, how to upload, download, FTP and Archie, the escape command, RFC's and how to find what you can't see. Now, what would you like?" "Lunch," decides the discouraged trainee.

This sentiment hit home for many of the 250-plus attendees, as Lipow's intention was to emphasize the need for trainers to know more than the topic and to know how people learn, giving special consideration to technolo- gy and to the Internet in particular.

Lipow, of Library Solutions Institute and Press, is coauthor of Crossing the Internet Threshold: An Instructional Handbook and coeditor of Staff Development: $A$ Practical Guide (ALA).

She described Internet as not so much an information "superhighway" but a "muddy road." Large computer databases, such as catalogs or the Internet, offer no visual cues to their size or organization, the range of subsets one needs to search through, or changes which have been made to them. Few adhere to Alan Kay's rule that a user should need only 15 seconds or less to figure out how to open the box, or to Walt Crawford's rule that a user should go into the system with only three layers or less to reach the objective. And, since systems are not standardized, learners can't reinforce their skills by generalizing concepts. The Internet is constantly changing and the resources it offers are generally unevaluated.

Lipow and Trish Ridgeway, The Handley Library, Virginia, provided essential background on adult training and learning concepts, while Debra Gilchrist, director of library and media services, Pierce College, and Jean Kent, Internet trainer at North Seattle Community College, dealt with setting the stage and training experiences respectively. Lipow reproduced Edgar Dale's "Cone of Experience" which indicates that, while people remember parts of what they read, hear, see, say, or write, the most effective learning occurs when people are hearing, saying, or seeing at the same time they are doing the real thing.

Lipow also pointed out four stages of learning: 1) unconscious/incompetent; 2) conscious/ incompetent, which leads staff to take workshops; 3) conscious/competent, which requires that staff be motivated to unlearn certain skills or behaviors and to practice new ones diligently until they become 4) unconscious/competent.

Lipow and Ridgeway described adult learners as 1) requiring a variety of teaching techniques; 2) wanting their experience recognized; 3) wanting to control what and how they learn; and 4) requiring solutions to immediate workplace problems.

(Programs cont. on page 512) 
Research Shoulldm? Be Lillke L Loolking for a Needlle in a Haystack.

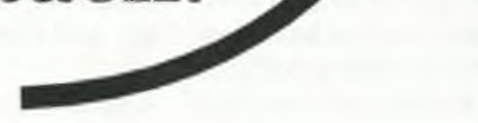

Conducting research is often like searching for a needle in a haystack. How would you like to search through a collection of needles instead? This is how we think of SIRS CD-ROM databases.

At SIRS, we believe it's what's inside that counts. So all the articles and documents on SIRS Researcher* and SIRS Government Reporter** CD-ROM programs are carefully chosen by the 25 members of our research staff. They read over 800 national and international sources looking for the best and most informative articles on a wide range of important subjects. SIRS takes the frustration out of research, making every search a hit. For a 60-day no-obligation preview, call 1-800-232-SIRS.

- Formerly SIRS Combined Text \& Index CD-ROM.

"* Selected full-text Government Documents.

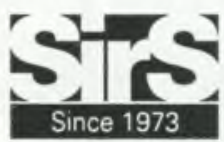

Social issues Resources Series, Inc PO Box 2348

Boca Raton, FL 33427-2348

Toll-free: 1-800-232-SIRS

Fax: $407 \cdot 994-4704$
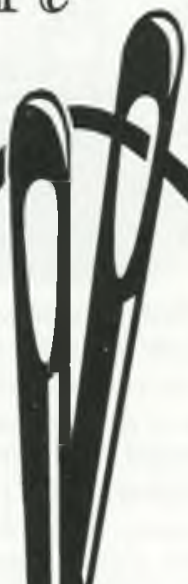